\title{
The Prevalence of Campylobacter spp. and Occurrence of Virulence Genes Isolated from Dogs
}

\author{
MAREK SELWET ${ }^{1}$, TOMASZ CŁAPA ${ }^{1}$, MARIOLA GALBAS ${ }^{2 *}$, RYSZARD SŁOMSKI ${ }^{2}$ \\ and FILIP PORZUCEK ${ }^{2}$ \\ ${ }^{1}$ Department of General and Environmental Microbiology, Poznań University of Life Sciences, Poznań, Poland \\ ${ }^{2}$ Department of Biochemistry and Biotechnology, Poznań University of Life Sciences, Poznań, Poland
}

Submitted 16 July 2014, revised 18 November 2014, accepted 15 December 2014

\begin{abstract}
This study was conducted to determine the prevalence of Campylobacter spp. isolated from dogs' faecal samples. From June 2012 to June 2013 , a total of 210 faecal samples from pet dogs living in different kennels $(n=210)$ were collected by the owners in Greater Poland Voivodeship, Poznań District, Poland. The study revealed that 105 out of 210 faecal samples (50\%) contained Campylobacter. The highest prevalence of Campylobacter spp. occurred in spring (81\%), followed by winter (64\%). The cadF gene was found in $100 \%$ of the isolates tested. The occurrence of the other genes was variable. The isolates from young dogs were characterised by higher occurrence of virulence genes.
\end{abstract}

Ke y words: Campylobacter spp., dogs, virulence genes

Salmonella spp., Escherichia coli and Campylobacter spp. are the main causes of diarrhoea both in animals and humans all over the world (Silva et al., 2011). According to the EFSA (EFSA, 2014), campylobacteriosis is the most frequently reported zoonotic disease. The most common sources of infection are products of animal origin: meat (primarily poultry), milk and water from natural reservoirs (Acke et al., 2011). The most frequently isolated species from dogs in Denmark are: Campylobacter upsaliensis 75\%, Campylobacter jejuni $19.4 \%$ and Campylobacter coli $0.7 \%$ (Hald et al., 2004). These Campylobacter species are more often isolated from dogs aged between 3 and 12 months than from older dogs (Hald et al., 2004). Moreover, some researchers also reported seasonal differences in prevalence (Rahimi and Saljooghian Esfahani, 2010; Andrzejewska et al., 2013). The factors which are associated with the pathogenicity of Campylobacter include: motility, chemotaxis as well as adhesion, and invasiveness (Bang et al., 2001; Krutkiewicz, 2008) and toxicity. These traits are associated with certain virulence genes identified from these bacteria, for example: flaA, cadF, iam and $c d t$ B (Biswas, 2011; Selwet and Galbas, 2012a). The investigations which have been carried out so far have revealed varying distribution of these virulence genes among strains. The aim of this study was to determine the frequency of occurrence of C. upsaliensis, C. jejuni and C.coli isolated from two different age groups of healthy dogs and from dogs with the symptoms of diarrhoea in Greater Poland Voivodeship, Poznań District. Apart from that, the frequency of occurrence of selected virulence genes was determined in the collected isolates. From June 2012 to June 2013, a total of 210 samples of faeces from pet dogs living in 5 kennels were collected by their owners in Greater Poland Voivodeship Poznań District, Poland. All the samples were obtained by veterinarian by means of swab kits with a transport substrate (Euro Tubo Collection Swab Rubi, Spain). The animals were aged as follows: 105 dogs were adult (> 12 months), 105 dogs were younger than 1 year. Diarrhoea was reported in 25 dogs. The owners of the other dogs did not report clinical symptoms of diarrhoea. The faecal samples were cultured at $42 \pm 1^{\circ} \mathrm{C}$ in Campy Selective Agar Base (Preston) (Neogen Europe, Scotland UK) for $48 \mathrm{~h}$ under microaerophilic conditions. DNA was extracted by means of CHELEX-100 chelating resin (Bio-Rad, CA, USA). Bacterial colonies were suspended in $100 \mu \mathrm{l}$ Tris buffer and $45 \mu \mathrm{l} 20 \%$ CHELEX and boiled for $10 \mathrm{~min}$. The samples were immediately placed on ice for $1 \mathrm{~min}$. and centrifuged at $13.000 \mathrm{~g}$ for $10 \mathrm{~min}$. at room temperature. A PCR was used for the detection of C. upsaliensis, C. jejuni and C. coli. (Andrzejewska et al., 2011). The following positive controls were included in the PCR: C. upsaliensis

* Corresponding author: M. Galbas, Department of Biochemistry and Biotechnology, Poznań University of Life Sciences, Poznań, Poland; e-mail: mariolagalbas@gmail.com 
Table I

The prevalence of Campylobacter spp. isolated from diarrhoeic and healthy dogs

\begin{tabular}{|c|c|c|c|c|c|c|}
\hline \multirow{2}{*}{ Sources } & $\begin{array}{c}\text { No. } \\
\text { of samples }\end{array}$ & $\begin{array}{c}\text { Campylobacter } \\
\text { spp. positive }\end{array}$ & $\begin{array}{c}\text { Campylobacter } \\
\text { upsaliensis }\end{array}$ & $\begin{array}{c}\text { Campylobacter } \\
\text { jejuni }\end{array}$ & $\begin{array}{c}\text { Campylobacter } \\
\text { coli }\end{array}$ \\
\hline \multirow{2}{*}{ Adult dogs } & Healthy & 95 & $37(38.9 \%)$ & $18(48.6 \%)$ & $15(40.5 \%)$ & $4(10.8 \%)$ \\
\cline { 2 - 7 } & Diarrhoeic & 10 & $5(50 \%)$ & $1(20 \%)$ & $2(40 \%)$ & $2(40 \%)$ \\
\hline \multirow{2}{*}{ Young dogs } & Healthy & 90 & $54(60 \%)$ & $29(53.7 \%)$ & $18(33.3 \%)$ & $7(13.0 \%)$ \\
\cline { 2 - 7 } & Diarrhoeic & 15 & $9(60 \%)$ & $2(22.2 \%)$ & $5(55.5 \%)$ & $2(22.2 \%)$ \\
\hline
\end{tabular}

ATCC 43954, C. jejuni ATCC 33560 and C. coli ATCC 33559. The presence of the flaA, cadF, $c d t \mathrm{~B}$ and iam genes was determined with the primers according to the authors (Nachamkin et al., 1993; Konkel et al., 1999; Bang et al., 2001; Carvalho et al., 2001). The statistical analysis was performed according to the GLM procedure of the SAS program (SAS, 1999) and the significance of differences was verified with Tukey's test. The prevalence of Campylobacter spp. was determined in the 210 faecal samples. PCR revealed the presence of Campylobacter spp. in 105 samples (50\%). Campylobacter spp. was isolated from 42 samples (40\%) from adult individuals and from 63 samples (60\%) from young dogs. The numbers of isolates differed significantly between the age groups $(\mathrm{P}<0.05)$. The most frequent species in the group of adult dogs were: $45.2 \%$ C. upsaliensis, $40.5 \%$ C. jejuni and $14.3 \%$ C. coli. In the group of young dogs the isolation percentage was similar, i.e. 49.2\% C. upsaliensis, 36.5\% C. jejuni and 14.3\% C. coli. There were significant differences observed in the prevalence of $C$. upsaliensis between the age groups of the dogs under study $(\mathrm{P}<0.05)$. Out of the 210 samples examined 25 samples derived from individuals with diarrhoea: 10 samples from adult dogs and 15 samples from young individuals (Table I). As far as the adult dogs are concerned, the predominant species were: 45.2\% C. upsaliensis, $40.5 \%$ C. jejuni and $14.3 \%$ C. coli whereas in the young dogs these were: $49.2 \%$ C. upsaliensis $36.5 \%$ C. jejuni and $14.3 \%$ C. coli. In summer
Table II

The seasonal prevalence of Campylobacter spp. isolated from dogs

\begin{tabular}{|l|c|c|c|}
\hline \multirow{2}{*}{ Seasons } & \multicolumn{2}{|c|}{ Sources } & \multirow{2}{*}{ Total } \\
\cline { 2 - 3 } & Adult dogs & Young dogs & \\
\hline Spring & $14 / 22(63.6 \%)$ & $20 / 20(100 \%)$ & $34 / 42(80.9 \%)$ \\
\hline Summer & $12 / 45(26.7 \%)$ & $20 / 40(50 \%)$ & $32 / 85(37.6 \%)$ \\
\hline Autumn & $10 / 28(35.7 \%)$ & $13 / 30(43.3 \%)$ & $23 / 58(39.6 \%)$ \\
\hline Winter & $6 / 10(60 \%)$ & $10 / 15(66.7 \%)$ & $16 / 25(64 \%)$ \\
\hline Total & $42 / 105$ & $63 / 105$ & $105 / 210$ \\
\hline
\end{tabular}

and autumn the frequency was similar with: $37.6 \%$ and $39.6 \%$, respectively (Table II). The analyses of the percentages of the selected virulence genes (Table III) revealed that the $c a d F$ gene was found in $100 \%$ of all the species. Also, the flaA gene was determined in $100 \%$ of C. jejuni and C. coli. As far as the $c d t B$ and iam genes are concerned, they were detected more frequently in the younger individuals. Although poultry is considered to be the main source of infection with Campylobacter spp. in humans, according to Biswas et al. (2011), the role of other animals as vectors spreading this bacterium should also be recognised. Parsons et al. (2010) in UK and Andrzejewska et al. (2013) in Poland reported that the frequency of Campylobacter spp. isolation in dogs ranges from $17 \%$ in Brazil and Argentina to $76.2 \%$ in Denmark. According to the study by Workman et al. (2005), the age of animals may also exert significant influence on the degree of occurrence

Table III

The number and percentages of virulence genes in Campylobacter spp. isolated from dogs

\begin{tabular}{|l|c|c|c|c|}
\hline \multirow{2}{*}{ Isolates/Animals } & \multicolumn{4}{|c|}{ Genes } \\
\cline { 2 - 5 } & cadF & flaA & cdtB & iam \\
\hline C. upsaliensis & $18(94.7 \%)$ \\
\hline Adult dogs $(\mathrm{n}=19)$ & $19(100 \%)$ & $18(94.7 \%)$ & $17(89.5 \%)$ & $30(96.8 \%)$ \\
\hline Young dogs $(\mathrm{n}=31)$ & $31(100 \%)$ & $30(96.8 \%)$ & $30(96.8 \%)$ & $15(88.2 \%)$ \\
\hline C. jejuni & \multicolumn{5}{|c|}{$17(100 \%)$} & $16(94.1 \%)$ & $21(91.3 \%)$ \\
\hline Adult dogs $(\mathrm{n}=17)$ & $17(100 \%)$ & $23(100 \%)$ & $23(100 \%)$ & \\
\hline Young dogs $(\mathrm{n}=23)$ & $23(100 \%)$ & & $5(83.3 \%)$ \\
\hline C. coli & $6(100 \%)$ & $6(100 \%)$ & $5(83.3 \%)$ & $8(88.9 \%)$ \\
\hline Adult dogs $(\mathrm{n}=6)$ & $9(100 \%)$ & $9(100 \%)$ & $8(88.9 \%)$ & \\
\hline Young dogs $(\mathrm{n}=9)$ &
\end{tabular}


of Campylobacter spp. Andrzejewska etal. (2013) reported the highest prevalence of Campylobacter spp. in dogs less than one year of age. Westgarth et al. (2008) observed that younger dogs were more likely to harbour C. upsaliensis and C. jejuni than adult animals. It may be related with younger dogs' lower immunity. So far the relationships between the occurrence of C. upsaliensis and gastritis as well as diarrhoea in dogs and humans have not been sufficiently explained. However, younger individuals are believed to be the main source of occurrence of gastritis and diarrhoea, as Rahimi et al. (2012) noted. Salihu et al. (2010), claim that age is not an indicator of the risk of contamination with C. jejuni. In our study C. upsaliensis was found significantly more often in younger dogs than adult animals whereas there was no such difference observed with C. jejuni and C. coli. Infections caused by Campylobacter spp. are usually correlated with the seasons of the year, although there are reports indicating that the isolations of Campylobacter spp. from dogs were more frequent in spring (Sandberg et al., 2002). Rahimi et al. (2012) recorded an increase of Campylobacter spp. isolations from young dogs aged under 1 year as well as from individuals which were over 1 year of age in warm months: in spring $-38.5 \%$ and in summer $-38.9 \%$. In our study, the frequency of isolation of Campylobacter spp. was higher in spring and in winter. The study by Rizal et al. (2010) showed that the following factors are involved in pathogenicity of Campylobacter spp.: motility and chemotaxis as well as adhesion and invasiveness. Nowadays it is believed that the following genes are responsible for the potential pathogenicity of Campylobacter spp.: the flaA gene influencing motility, cadF - affecting adhesion, $c d t \mathrm{~B}$ - responsible for toxin production (cytolethal distending toxin) and iam - determining invasiveness (Krutkiewicz, 2008). In our investigations the cadF gene was determined in $100 \%$ in C. upsaliensis, C. jejuni and C. coli. Biswas et al. (2011) confirmed the occurrence of this gene in $100 \%$ of the examined C. jejuni strains derived from human clinical studies and cow faeces. Selwet and Galbas (2012a; $2012 \mathrm{~b}$ ) observed that the cadF and flaA genes were found in $100 \%$ of C.coli and C. jejuni isolated from broilers, porkers, calves and piglets. All the strains of C. jejuni, C. coli C. upsaliensis under analysis carried the $c d t \mathrm{~B}$ gene encoding the protein exhibiting toxic properties, i.e. cytolethal distending toxin. This exotoxin causes the inhibition of the cell cycle and DNA degradation in the host (Lara-Tejero, 2001) and it may cause the death of sensitive eukaryotic cells (Heywood et al., 2005). CDT is composed of three subunits: CdtA, $\mathrm{CdtB}$ and $\mathrm{CdtC}$, which are encoded by three genes: $c d t \mathrm{~A}, c d t \mathrm{~B}$ and $c d t \mathrm{C}$. All the three subunits are required for full activity (Rozynek et al., 2005). In our study the iam gene, which is responsible for invasiveness, was found in all the strains of Campylobacter spp. Carvalho et al. (2001) observed in their studies that the iam gene was detected most frequently in the strains of $C$. jejuni rather than in C. coli. The PCR analysis of stool isolates collected from dogs on farms in Wielkopolska (Greater Poland) region revealed the presence of Campylobacter spp. with the predominance of C.upsaliensis, which occur more frequently in young animals. The presence of C. jejuni and C. coli was frequently identified in adult dogs with the symptoms of diarrhoea, whereas C. jejuni was identified in young dogs. The correlation between diarrhoea and the presence of these bacteria should be taken into consideration in veterinary practice.

\section{Literature}

Acke E., C. Carroll, A. O’Leary, K. McGill, L. Kelly, A. Lawlor, R.H. Madden, L. Moran, P. Scates, E. McNamara and others. 2011. Genotypic characterization and cluster analysis of Campylobacter jejuni isolates from domestic pets, human clinical cases and retail food. Ir. Vet. J. 64: 6.

Andrzejewska M., J.J. Klawe, B. Szczepańska and D. Śpica. 2011. Occurrence of virulence genes among Campylobacter jejuni and Campylobacter coli isolates from domestic animals and children. Pol. J. Vet. Sci. 2:207-211.

Andrzejewska M., B. Sczepańska, J.J. Klawe, D. Śpica and M. Chudzińska. 2013. Prevalence of Campylobacter jejuni and Campylobacter coli species in cats and dogs from Bydgoszcz (Poland) region. Pol. J. Vet. Sci. 1: 115-120.

Bang D.D., F. Scheutz, P. Ahrens, K. Pedersen, J. Blom and M. Madsen. 2001. Prevalence of cytolethal distending toxin $(c d t)$ genes and CDT production in Campylobacter spp. isolated from Danish broilers. J. Med. Microbiol. 50:1087-1094.

Biswas D., S.J. Hannon, H.G.G. Townsend, A. Potter and B.J. Allan. 2011. Genes coding for virulence determinants of Campylobacter jejuni in human clinical and cattle isolates from Alberta, Canada, and their potential role in colonization of poultry. Int. Microbiol. 4: 25-32.

Carvalho A.C., G.M. Ruiz-Palacios, P. Ramos-Cervantes, L.E. Cervantes, X. Jiang and L.K. Pickering. 2001. Molecular characterization of invasive and noninvasive Campylobacter jejuni and Campylobacter coli isolates. J. Clin. Microbiol. 39: 1353-1359.

European Food Safety Authority and European Centre for Disease Prevention and Control. The European Union Summary Report on antimicrobial resistance in zoonotic and indicator bacteria from humans, animals and food in 2012. EFSA Journal 2014. $12,3590$.

Hald B., K. Pedersen, M. Waino, J.Ch. Jorgensen and M. Madsen. 2004. Longitudinal study of the excretion patterns of termophilic Campylobacter spp. in young pet dogs in Denmark. J. Clin. Microbiol. 42: 2003-2012.

Heywood W., B. Henderson and S.P. Nair. 2005. Cytolethal distending toxin: creating a gap in the cell cycle. J. Med. Microbiol. 54: 207-216.

Konkel M., S.A. Gray, B.J. Kim, S.G. Gravis and J. Yoon. 1999. Identification of enteropathogens Campylobacter jejuni and Campylobacter coli based on the cadF virulence gene and its product. J. Clin. Microbiol. 37: 510-517.

Krutkiewicz A. 2008. Campylobacteriosis in humans and animals (In Polish). Życie Wet. 83: 285-288. 
Lara-Tejero M. and J.E. Galan. 2001. $C d t A, c d t B$ and $c d t C$ form a tripartite complex that is required for cytolethal distending toxin activity. Infect. Immun. 69: 4358-4365.

Nachamkin I., K. Bohachic and C.M. Patton. 1993. Flagellin gene typing of Campylobacter jejuni by restriction fragment length polymorphism analysis. J. Clin. Microbiol. 31: 1531-1536.

Parsons B.N., C.J. Porter, R. Ryvar, J. Stavisky, N.J. Williams, G.L. Pinchbeck, R.J. Birtles, R.M. Christley, A.J. German, A.D. Radford and others. 2010. Prevalence of Campylobacter spp. in a cross-sectional study of dogs attending veterinary practices in the UK and risk indicators associated with shedding. Vet. J. 184: 66-70. Rahimi E. and M.H. Saljooghian Esfahani. 2010. Seasonal prevalence of Campylobacter jejuni and Campylobacter coli in raw chicken meat using PCR assay. Meddle-East J. Sci. Res. 6: 329-332.

Rahimi E., A. Chakeri and K. Esmizadeh. 2012. Prevelence of Campylobacter species in fecal samples from cats and dogs in Iran. Slov. Vet. Res. 49: 117-122.

Rizal A., A. Kumar and A.S. Vidyarthi. 2010. Prevalence of pathogenic genes in Campylobacter jejuni isolated from poultry and human. Internat. J. Food Safety. 12: 29-34.

Rozynek E., K. Dzierzanowska-Fangrat, P. Jozwiak, J. Popowski, D. Korsak and D. Dzierzanowska. 2005. Prevalence of potential virulence markers in Polish Campylobacter jejuni and Campylobacter coli isolates obtained from hospitalized children and from chicken carcasses. J. Med. Microbiol. 54: 615-619.
SAS. 1999. User's guide. Statistics version $7^{\text {th }}$ ed. SAS Inst Inc Cary NC

Salihu M.D., A.A. Magaji, J.U. Abdulkadir and A. Kolawal. 2010. Survey of thermophilic Campylobacter species in cats and dogs in north-western Nigeria. Vet. Ital. 46: 425-430.

Sandberg M., B. Bergsjo, M. Hofshagen, E. Skjerve and H. Kruse. 2002. Risk factors for Campylobacter infection in Norwegian cats and dogs. Prev. Vet. Med. 55: 241-253.

Selwet M. and M. Galbas. 2012a. Monitoring of selected genes in Campylobacter jejuni and Campylobacter coli isolates from domestic animals. Bull. Vet. Inst. Pulawy. 56: 283-286.

Selwet M. and M. Galbas. 2012b. Impact of probiotic on the presence of selected virulence genes and drug-resistance among Campylobacter coli isolated from piglets. Bull. Vet. Inst. Pulawy. 56: 507-511.

Silva J., D. Leite, M. Fernandes, C. Mena, P.A. Gibbs and P. Teixeira. 2011. Campylobacters pp.as a foodborne pathogen: a review Frontiers in Microbiology Food Microbiology. 2: 1-12

Westgarth C., G.L. Pinchbeck, J.W. Bradshaw, S. Dawson, R.M. Gaskell and R.M. Christley. 2008. Dog-human and dog-dog interactions of 260 dog-owning households in a community in Cheshire. Vet. Rec. 162: 436-442.

Workman S.N., G.E. Mathison and M.C. Lavoie. 2005. Pet Dogs and Chicken Meat as Reservoirs of Campylobacter spp. in Barbados. J. Clin. Microbiol. 43: 2642-2650. 